\title{
Effect of high-glycaemic meals in the last trimester of pregnancy on offspring birth weight and postnatal growth in sheep
}

\author{
N. A. Smith ${ }^{1}$, F. M. McAuliffe ${ }^{2,3}$, K. Quinn ${ }^{1}$, P. Lonergan ${ }^{1,3}$ and A. C. O. Evans ${ }^{1,3}$ \\ ${ }^{1}$ School of Agriculture Food Science and Veterinary Medicine, ${ }^{2}$ School of Medicine and Medical Science and ${ }^{3}$ UCD \\ Conway Institute of Biomolecular and Biomedical Research, College of Life Sciences, University College Dublin, Belfield, \\ Dublin 4, Republic of Ireland
}

Experimental evidence indicates a direct relationship between maternal glucose levels and infant birth weight in human subjects ${ }^{(1)}$. The present study has investigated whether feeding hyperglycaemic meals in the third trimester of pregnancy in the ewe results in heavier lambs at birth with faster growth rates in early postnatal life.

For the last trimester of pregnancy (days 98-147 of gestation) ewes were blocked on weight, age and litter size and randomly assigned to one of two treatments: $100 \mathrm{ml}$ propylene glycol (PG) twice daily ( $n 50) ; 100 \mathrm{ml}$ water twice daily (control (C); $n 52)$. On days 110 and 140 of gestation a subsample of ewes from each of the two treatment groups (twelve per group) were randomly selected and blood samples were collected every 30-60 min for $17 \mathrm{~h}$ to determine the ewe's glucose and insulin response to PG or water (Figure). The birth weight and gender of the lambs were recorded. Body dimensions were also measured and a ponderal index was calculated as weight/ height $^{3}$. The offspring were weighed at intervals of 8 weeks from birth until slaughter at a live weight of about $40 \mathrm{~kg}$.

Oral administration of PG resulted in elevated plasma glucose and insulin concentrations for $2 \mathrm{~h}$ post administration compared with $\mathrm{C}$ ewes. Lambs (C, $n$ 80; PG, $n$ 70) born to ewes fed high-glycaemic meals had a higher birth weight (kg; PG, 5.27 (SE 0.11 ); C, 5.01 (SE 0.09); $P=0.032$ ), higher basal plasma glucose concentrations (mm/l; PG, 3.88 (SE 0.29); C, 2.87 (SE 0.17); $P<0.001)$, ponderal index $(P=0.043)$ and reached a similar $(P>0.05)$ slaughter weight $(20.0-20.6 \mathrm{~kg})$ at an earlier age $(\mathrm{d} ; \mathrm{PG}, 166.0(\mathrm{SE} 6.75)$; C, 183.4 (SE 7.02$)$; $P=0.039)$ when compared with the $\mathrm{C}$ group.

In conclusion, feeding high-glycaemic meals to ewes in the third trimester of pregnancy resulted in offspring with a heavier birth weight, higher basal plasma glucose concentrations and faster growth rates in early postnatal life.
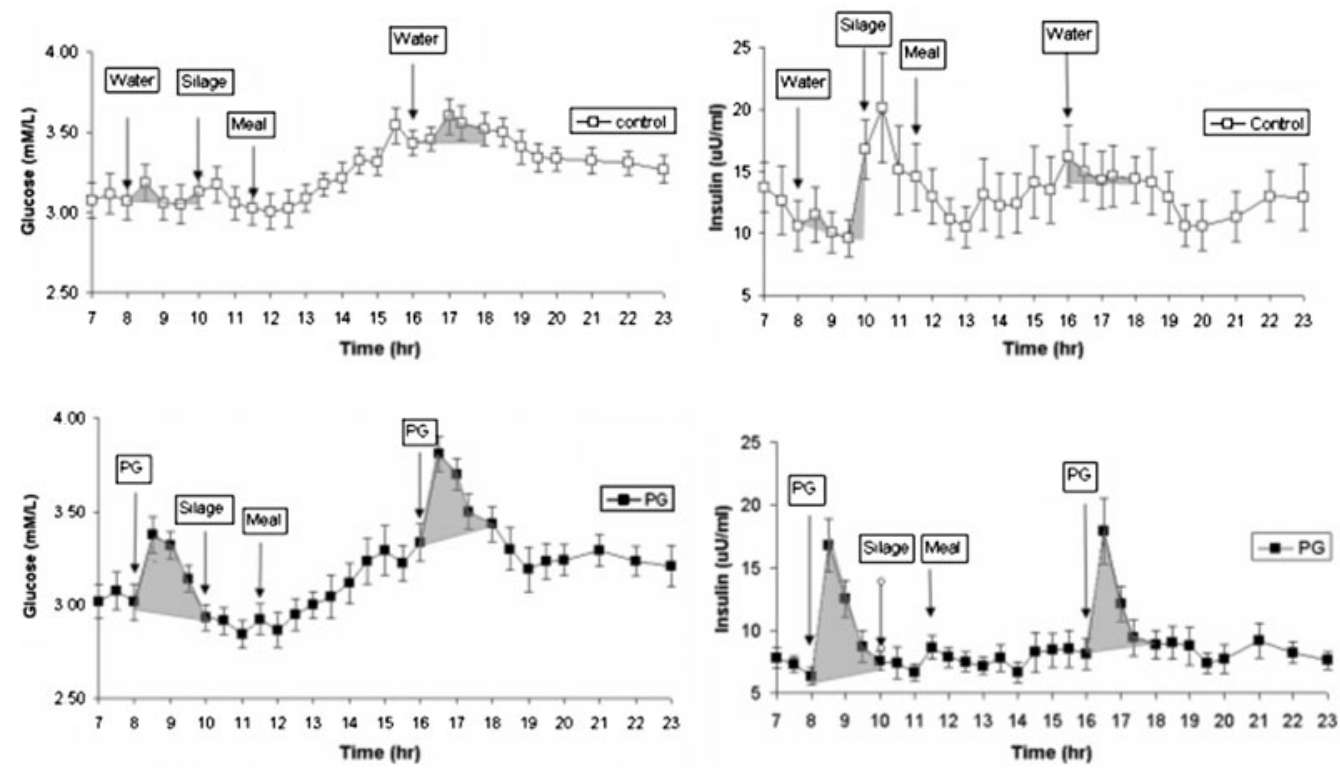

Figure. Glucose and insulin concentrations on day 109 of gestation in ewes administered propylene glycol (PG; $n$ 12) or water ( $n$ 12) daily from day 98 of gestation. Ewes received $100 \mathrm{ml}$ PG or water (control) at 08.00 hours and again at 16.00 hours. The response to propylene glycol or water was calculated as area under the curve for the $2 \mathrm{~h}$ post administration. Values are means with their standard errors represented by vertical bars. 